\title{
A Framework for Evaluating the Customer Wait Experience
}

\author{
Kelly A. McGuire, SAS, Institute, Inc \\ Sheryl E. Kimes and Michael Lynn, Cornell University \\ Madeline E. Pullman, Portland State University \\ Russell C. Lloyd, Cornell University
}

Purpose - The purpose of this paper is to propose and test a model which defines the psychological processes that mediate the relationship between perceived wait duration (PWD) and satisfaction. This model will provide a framework for evaluating the impact of situational and environmental variables in the servicescape on customer reaction to the wait experience.

Design/methodology/approach - The approach included one field study and two laboratory experiments in which subjects participated in a service with a pre-process wait and evaluated their experience on a survey.

Findings - Perceived wasted time, perceived control, perceived boredom, and perceived neglect mediated the relationship between PWD and wait experience evaluation. When tested using filled versus unfilled wait time as the situational variable, the model showed that having something to do during the wait decreased perceived boredom, resulting in a more positive wait experience.

Research limitations/implications - The services used in this paper were functional (as opposed to hedonistic) in nature and wait durations were a maximum of ten minutes.

Originality/value - The framework established in this paper can be used to evaluate customer reaction to the elements of the waiting environment design, which will help managers design waiting environments that maximize customer satisfaction, and help researchers to understand changes in the relationship between PWD and satisfaction under different environmental conditions.

Why does the five-minute wait at the pharmacy seem interminable, when the 30 min wait for a table spent at the bar with friends flies by? People are willing to spend as much as 50 percent of their time during an amusement park visit waiting in line (Koseluk, 2004), but complain (and balk) if it takes more than ten minutes to get a cup of coffee at the local coffee shop. 
The wait is often treated as ancillary to the core service experience, when in fact, it is the first interaction in the sequence of experiences that customers have with the firm (Chase and Dasu, 2001; Dixon and Verma, 2009). The nature and order of these experiences can have an impact on overall service satisfaction (Chase and Dasu, 2001; Dixon and Verma, 2009). The waiting environment is the first contact the customer has with the servicescape, a critical component of impressions of the service encounter (Bitner, 1992). Although the link between waiting and service satisfaction is well documented in the literature (Dube-Rioux et al., 1989; Katz et al., 1991; Taylor, 1994; Houston et al., 1998; Weijters et al., 2007) the relationship can change when situational and environmental factors in the waiting environment component of the servicescape are altered (Baker and Cameron, 1996). Moreover, the processes that might mediate this effect are not well understood.

Research has suggested that customers experience the service encounter in a series of snapshots of extreme moments (Burt et al., 1995; Nguyen and Belk, 2007), and that "peak" experiences play a more important role in the overall impression of the service encounter than other elements of the service experience (Verma et al., 1999; Dixon and Verma, 2009). During a pre-service wait, customers are part of the servicescape (Bitner, 1990), even if they have yet to begin the service encounter. Satisfaction with the waiting environment has been shown to strongly influence waiting satisfaction, and when customers are dissatisfied with the wait, they must be more satisfied with the service to have the same level of loyalty as customers who were satisfied with the wait (Bielen and Demoulin, 2007). Therefore, in order to maintain satisfaction, managers need to understand and manipulate customer reactions to elements of the waiting environment.

In this paper, we propose a methodology to evaluate the impact of specific elements of the servicescape and the service design on customer wait experience. First, we propose a model of the relationship between perceived wait time and satisfaction that considers the impact of various psychological mediators, and then we alter specific environmental elements to test the effectiveness of the framework. First, a brief review of research on customer perceptions of the wait experience and the psychological factors that contribute to wait perceptions is presented. Next, a model which outlines the relationships between the psychological factors and customers' wait perceptions is proposed. The model is then tested under three wait conditions, and the theoretical and managerial results are discussed. 


\section{Literature Review}

\section{A. Perceived Time, Satisfaction, and the Wait Experience}

In general, research has shown that as waiting time increases, satisfaction decreases (Davis and Volmann, 1990; Taylor, 1994). Customers tend to overestimate waiting time (Hornik, 1984; Feinberg and Smith, 1989; Katz et al., 1991; Pruyn and Smidts, 1998), and these estimated wait durations have an equal, if not greater, effect on satisfaction than objective waiting time (Katz et al., 1991; Tom and Lucey, 1997; Davis and Heineke, 1998; Pruyn and Smidts, 1998). In general, as perceived wait duration (PWD) increases, affective reactions to the wait become more negative (Folkes et al., 1987; Katz et al., 1991; Hui et al., 1998; Pruyn and Smidts, 1998) and waits become less acceptable (Clemmer and Schneider, 1989; Chebat and Filiatrault, 1993; Chebat and Chebat, 1995; Antonides et al., 2002). Additionally, there is a positive relationship between affective reactions to the wait and service encounter satisfaction (Dube-Rioux et al., 1989; Taylor, 1994; Hui et al., 1997; Davis and Heineke, 1998; Pruyn and Smidts, 1998; Bielen and Demoulin, 2007).

\section{B. Influence of Situational Variables}

The relationship between wait duration estimates, wait evaluations and satisfaction may change in the presence of certain situational or environmental elements in the wait environment. For example, conventional wisdom and common practice holds that occupying customers during the wait will cause them to lose track of the passage of time (Zakay, 1989), and feel as though their wait are shorter, (Maister, 1985; Larson, 1987) which should lead to increased satisfaction. However, research into the effect of time filling activities has not conclusively established this effect.

Pruyn and Smidts (1998) found that customers who watched television during a wait for a clinic appointment had increased perceived wait time and lowered satisfaction, over customers who did nothing during the wait. Similarly, Chebat and Filiatrault (1993) found that customers who filled out deposit slips during their wait in a bank queue perceived longer wait duration and had lower satisfaction than those who did nothing. Conversely, Katz et al. (1991) found that when an electronic news board was installed in a bank lobby, waiting customers reported higher satisfaction, but perceived wait time stayed the same.

Both Pruyn and Smidts (1998) and Chebat and Filiatrault (1993) suggested that the subjects in their studies found the available activities boring or routine. Katz et al. (1991) found that subjects who viewed an electronic news board during the wait reported higher levels of interest than those with 
nothing to do, concluding that "enlightening and engaging" customers during the wait results in higher satisfaction. However, none of the studies offered any empirical evidence for their conclusions. Understanding the psychological processes that drive the relationship between perceived time and satisfaction may help establish a framework for understanding these conflicting results.

\section{Psychological Factors}

Psychologists have suggested that waiting is objectionable because it wastes time, takes control away from customers, creates boredom, leads to feelings of crowding and neglect, and delays gratification (Schwartz, 1975; Osuna, 1985; Carmon et al., 1995). Although research seems to imply that the longer the wait duration, the greater the impact on the customers' psychological well being (Figure 1), no empirical research has examined the effect of these proposed mediators.

Perceived wasted time. Time is considered to be a scarce resource, which should be carefully spent (Jacoby et al., 1976; Leclerc et al., 1995). Time spent waiting increases the investment that must be made to obtain a service and reduces the utility that can be derived from it (Schwartz, 1975; Berry et al., 2002). The more valuable the customers' time, the more negative their perception of those that waste it (Osuna, 1985; Antonides et al., 2002).

Perceived control. Control is defined as the need to demonstrate one's competence, superiority and mastery over the environment (White, 1959). Increased perceptions of control have a significant, positive impact on human physical and psychological well-being (Staub et al., 1971; Langer and Rodin, 1976; Szpiler and Epstein, 1976; Sherrod et al., 1977, Burger, 1987, Hui and Bateson, 1991). Waiting may create a feeling of helplessness, where the waiter is essentially "immobile," unable to move for fear of losing her spot in the queue (Schwartz, 1975). Customers try to control their waiting experience by deciding whether to join the queue (Hui and Bateson, 1991), picking deterministic waits over uncertain waits (Leclerc et al., 1995), and ascertaining and tracking waiting times (Hui and Tse, 1996; Leclerc et al., 1995).

Perceived boredom. Boredom arises when an individual "does not get enough interesting information" (Klapp, 1986). Time often seems to move more slowly to someone who experiences boredom, this results from the way in which the human mind measures the passage of time (Zakay, 1989), combined with the infrequency of events perceived as notable. In other words, having nothing to do during the wait results in idleness, which leads to boredom (Maister, 1985; Larson, 1987). In a study of a bank queue, subjects who reported lower interest levels during the wait also reported lower satisfaction with the service encounter (Katz et al., 1991). 
Perceived neglect. Parasuraman et al. $(1985,1989)$, demonstrated that the degree to which a firm understands and responds to consumers' needs (responsiveness) and the degree to which they provide caring and individual attention (empathy) are important components of perceived service quality. When customers are forced to wait, the firm might be perceived as being unresponsive or not empathetic. Feelings of neglect during a wait cause anxiety and uncertainty (Taylor, 1994; Hui et al., 1998), which negatively impact the experience.

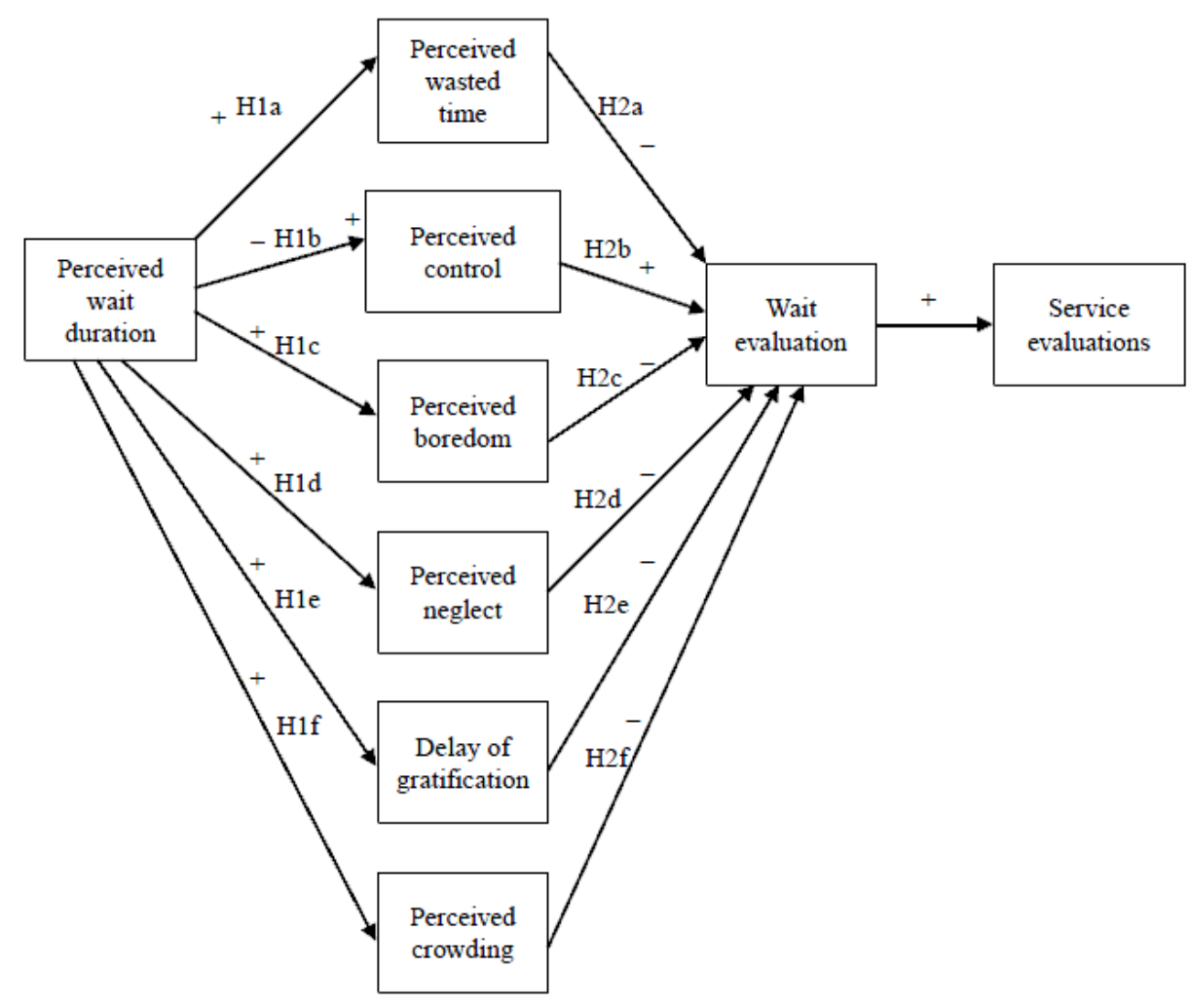

Perceived crowding. Crowding describes a perceptual reaction to density, a physical condition that occurs in an environment when space is limited (Stokols, 1972). Feelings of crowding arise when the people notice the number of customers in the environment, and it begins to cause feelings of discomfort (Stokols, 1972). Perceived crowding leads to feelings of stress, anxiety and irritation (Saegert et al., 1975; Sundstrom, 1975), increased sensitivity to others (Valins and Baum, 1973), and generation of negative interpersonal affect (Stokols et al., 1973, Baum and Greenburg, 1975). Langer and Saegart (1977), for example, found that subjects who felt crowded while shopping in a grocery store were less satisfied with their shopping experience than those who did not perceive the environment to be crowded. 
Delay of gratification. Delay of gratification is the process of abstaining from the impulse to take a smaller reward now (achieving instant gratification) to wait for a larger reward later (Mischel, 1974). A wait blocks the customer from their desired reward (the good or service they wait for) (Nie, 2000). Waiting is painful because it is a deferral of gratification imposed by an outside authority (Schwartz, 1975). This deferral of gratification is particularly painful in pre-process waits, when the "reward" lies ahead, and the wait threatens the achievement of that reward (Lewin, 1943; Dube-Rioux et al., 1989; Hui et al., 1998).

\section{Occupied Time and Activity Type}

The conflicting evidence of the influence of occupied time on consumers' reactions to the wait experience discussed above suggests that it might be useful to evaluate the impact of situational and environmental variables on PWD, the psychological factors, and wait evaluations. The results of previous studies (Katz et al., 1991; Chebat and Filiatrault, 1993; Hui et al., 1997; Pruyn and Smidts, 1998), suggest that different types of time fillers have different effects on the processes underlying the relationship between waiting and satisfaction.

Two activity types are hypothesized to influence waiting perceptions, choice and degree of involvement (passive vs active activities). Choice has been shown to increase satisfaction and perceptions of control (Averill, 1973; Hui and Bateson, 1991, Namasivayam and Hinkin, 2003). Hui and Bateson (1991), in their study of the impact of choice and crowding on control and satisfaction, found that customers who chose to enter a crowded service environment felt more control and were more satisfied that customers who were given no choice.

Research has shown that customers tend to lose track of time when participating in activities and experiences that are active or engaging (Burnside, 1971; Troutwine and O'Neal, 1981; Kahneman, 1994; Csikszentmihalyi, 1996, 1997). Troutwine and O'Neal (1981), for example, found that subjects underestimated the duration of the time interval when asked to work on an interesting task and overestimated when asked to work on a boring task. Filling the time with active rather than passive activities may draw attention away from the passage of time (Zakay, 1989), reduce boredom (Klapp, 1986; Csikszentmihalyi, 1996, 1997), and improve affective reaction to the waiting experience.

In order to evaluate these hypotheses one field study (Study 1 ) and two laboratory experiments (Experiments 2 and 3) were conducted. The field study was exploratory, to investigate all of the potential mediators, and the two laboratory experiments tested the model in a controlled environment. 


\section{Study 1}

Figure 1 show the hypotheses evaluated in Study 1 (H1a-f and H2a-f).

\section{A. Methodology}

Study 1 was a field study conducted in an a-la-carte university dining hall. Subjects were approached after purchasing their lunch and offered $\$ 5$ gift card to a local coffee shop in exchange for filling out a three-page survey. Existing, multi-item scales were used in the survey instrument when possible (Churchill, 1979), and included:

- Perceived time (time estimated to the nearest minute and cognitive wait appraisal (short/long), Chebat and Filiatrault, 1993, Pruyn and Smidts, 1998).

- Perceived wasted time (developed for this study from Schwartz, 1975, Osuna, 1985, Houston et al., 1998).

- Perceived control (Hui and Bateson, 1991).

- Perceived boredom (adapted from the enduring involvement scale, Higie and Feick, 1989).

- Perceived neglect based on the responsiveness and empathy constructs from the SERVQUAL scale (Parasuraman et al., 1985, 1988).

- Delay of gratification (developed for this study from Mischel, 1974).

- Perceived crowding (Hui and Bateson, 1991).

- Wait experience evaluation (affective response: Hui and Tse, 1996, Hui et al., 1998, acceptability: Hui and Tse, 1996, disconfirmation of wait time expectations: Hui and Tse, 1996).

- Service evaluation (Hui and Tse, 1996 and Hui et al., 1998 from Ajzen and Fishbein, 1980).

- Control variables (frequency of use of the dining hall, a categorical report of the subject's waiting time activity, age, and gender).

The survey items were pre-tested on a similar population. Exploratory factor analysis on the data from Study 1 using principal components analysis with Promax rotation, showed that all measures for the hypothesized constructs exhibited strong validity (loading singularly and significantly on one factor) and reliability (Cronebach's alpha ranging from 0.67 to 0.88 ). The items for each scale were then averaged to form composite scores. 


\section{B. Results}

The average age of the 186 respondents in Study 1 was 20.3 years with a range from 18 to 58 . About one third of the respondents (32.3 percent) were male and two thirds were female $(67.7$ percent). Subjects reported average PWD of 2.4 minutes, with a range from 0 to ten minutes.

One-tailed Sobel tests were used to evaluate the hypothesized mediators of the effects of perceived wait time on satisfaction, since directionality was hypothesized. Sobel tests indicated that perceived wasted time (Sobel test: $Z=-3.88, p<0.000$ ), perceived control (Sobel test: $Z=-1.94, p=$ 0.025), perceived neglect (Sobel test: $Z=-24.62, p<0.000$ ), delay of gratification (Sobel test: $Z=-1.59$, $p=0.055$ ), and perceived crowding (Sobel test: $Z=-2.92, p<0.000$ ) were significant mediators but that, perceived boredom (Sobel test: $Z=-1.19, p=0.25$ ) was not significant. (Beta coefficients for the regression equations used in the Sobel tests are included in Table I). These results support H1a, b, d, and $\mathrm{f}$, and $\mathrm{H} 2 \mathrm{a}, \mathrm{b}, \mathrm{d}$, and $\mathrm{f}$. A multiple regression found that PWD was significantly related to wait evaluations even after controlling for the mediating variables $(B=-0.097, F=12.883, p<0.0001)$, indicating that the psychological factors only partially mediated this relationship (Baron and Kenny, 1986).

Although perceived boredom could not be said to be a mediator of the relationship between PWD and wait evaluations, analysis of the control variable for wait time activity showed that having something to do during the wait (talking with a friend or on the phone) decreased perceived boredom by 1.12 points (on an eight point scale, $p<0.000$ ) over doing nothing. Although not intentionally tested or manipulated in this study, this result provided preliminary support for $\mathrm{H} 3 \mathrm{~b}$, that active time fillers reduce boredom. Finally, correlation analysis indicated a significant $(p<0.0001)$ and positive relationship between wait experience evaluations and service encounter evaluations ( $r 2=0.289$ ).

\section{Discussion}

Perceived wasted time, perceived control, perceived neglect, delay of gratification and perceived crowding were partial mediators of the relationship between PWD and wait evaluations. Therefore, the longer people feel as though they have waited, the less control, more wasted time, more neglect, more delay of gratification and the more crowded they feel, which leads to a more negative reaction to the wait. These preliminary results suggest that firms would benefit from paying attention to the elements in their wait environment that would impact these psychological factors, such as adding design elements that reduce crowding, training staff to acknowledge waiting guests to reduce neglect perceptions, or creating cues within the environment that make the customers feel as though the firm is paying attention to their needs. 
This exploratory study provided initial support for the proposed wait perception framework. Although mediation is indicated, actual wait duration was not captured in this study, so it was not possible to establish the directionality of the relationship between variability in time and variability in the study measures. For example, it is possible that increasing feelings of wasted time could cause subjects wait duration estimates to increase. In order to establish directionality, a laboratory experiment was designed in which actual wait time could be manipulated and the servicescape and service experience controlled.

\begin{tabular}{|c|c|c|c|c|c|}
\hline \multirow{2}{*}{$\frac{\text { Construct }}{\text { Perceived crowding }}$} & \multicolumn{2}{|c|}{ PWD } & \multicolumn{2}{|c|}{ Wait evaluation } & \\
\hline & 0.201 & $(0.060 * * * * *)$ & -0.186 & $(0.031 * * *)$ & \\
\hline Perceived neglect & 0.179 & $\left(0.031^{* * * *}\right)$ & -0.432 & $(0.056 * * * *)$ & \\
\hline Perceived control & -0.104 & $(0.050 * * * *)$ & 0.211 & $(0.038 * * *)$ & Table I. \\
\hline Perceived wasted time & 0.205 & $\left(0.043^{* * * *}\right)$ & -0.280 & $\left.(0.042 * * *)^{*}\right)$ & Study 1: beta coefficients \\
\hline Delay of gratification & 0.120 & $(0.042 * * * *)$ & -0.094 & $(0.049 * * *)$ & from separate regressions \\
\hline Perceived boredom & 0.069 & $\left(0.057^{* * * * *}\right)$ & -0.133 & $(0.035 * * *)$ & of perceived time on each \\
\hline $\begin{array}{l}\text { Notes: }{ }^{*} p<0.0001 \text {, } \\
\text { parentheses }\end{array}$ & .001 & $.01, \quad * * * * p<0.05$ & $* * * * * 1$ & $p$-values in & $\begin{array}{r}\text { mediator on wait } \\
\text { evaluations }\end{array}$ \\
\hline
\end{tabular}

\section{Study 2}

The purpose of Study 2, a laboratory experiment, was to evaluate the relationships discovered in Study 1 in a controlled environment to determine whether the variability in the psychological factors was caused by variability in actual time. The model for Study 2 is shown in Figure 2. Perceived wasted time, perceived control, perceived boredom, and perceived neglect were hypothesized to mediate the relationship between both actual and PWD and wait experience evaluations, which is hypothesized to have a positive relationship with service encounter evaluations. The laboratory study was a virtual queue, making perceived crowding an irrelevant construct, and delay of gratification, barely significant in Study 1, was also eliminated for this functional service context.

\section{A. Methodology}

Undergraduate subjects were recruited under the pretext of evaluating a new dating web site developed by undergraduate entrepreneurs (Hui and Tse, 1996; Hui et al., 1998). They were asked to report to a computer lab on campus, and when they attempted to log into the web site, they were told that due to limited capacity on the testing server, there would be a wait to log in. They were then randomly assigned to one of three empty, variable duration waiting conditions: no wait (control), three minute wait and ten minute wait [1]. The subjects received no information about the expected duration of the wait either before or during the experiment. The majority of the 102 subjects participated in 
Experiment 2 for course credit, but some received a $\$ 5$ gift card to a local coffee shop [2]. Subjects ranged in age from 18 to 35 years (mean 20.1 years) and 31.4 percent were male (68.6 percent female), making the demographic profile very similar to Study 1.

\section{B. Results}

Confirmatory factor analysis (CFA) in SAS 9.13 validated the underlying factor structure of the study measures. All t-values were significant and most factor loadings were .0 .40 . The $\chi^{2} / \mathrm{df}$ ratio was within the desirable range of between 1 and 3 (Marsh and Hocevar, 1985). The normed fit index (0.87) and comparative fit index (0.85) were close to the recommended range of .0.90 (Bentler, 1990). Composite reliabilities are as follows: perceived wasted time (0.90), perceived control (0.85), perceived boredom (0.90), perceived neglect (0.82), wait evaluation (0.92), service evaluation (0.87). Scale items were averaged for the subsequent analysis (Table II).

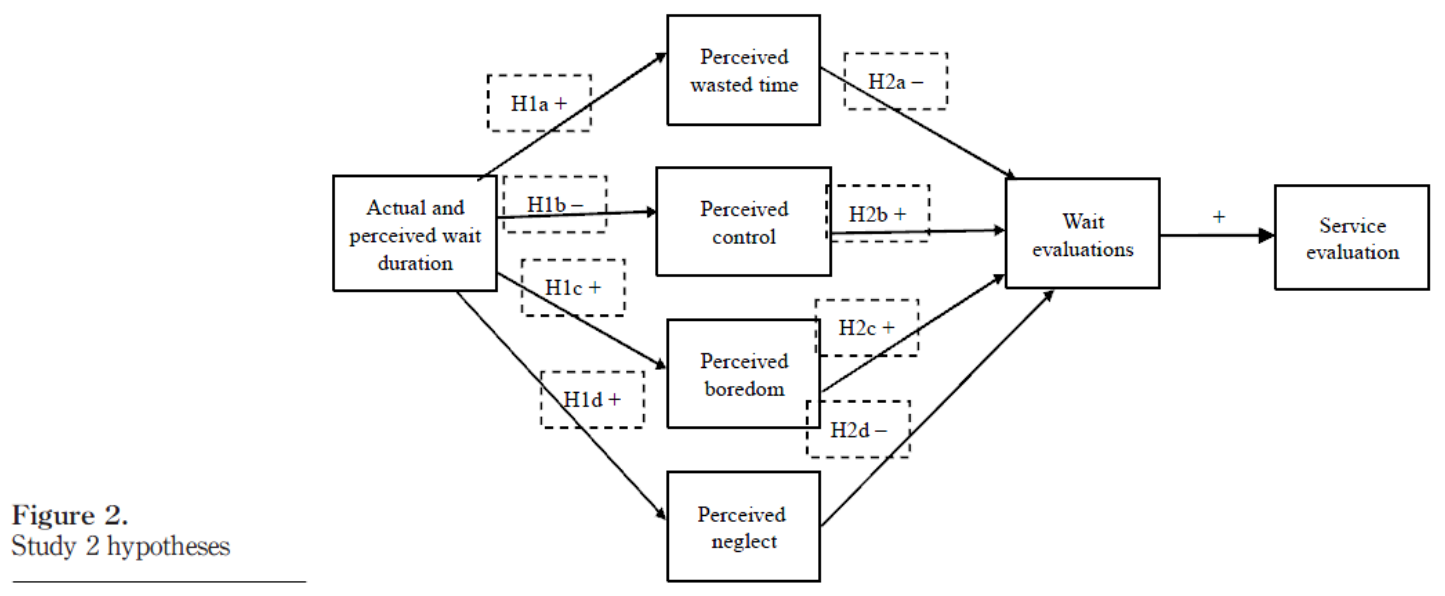

One-tailed mediation tests indicate that perceived boredom (Sobel test: $Z=-3.56, p<0.000$ ), perceived control (Sobel test: $Z=-2.37, p<0.008$ ), perceived wasted time (Sobel test: $Z 1 \frac{1}{4} 24.11, p<0.000$ ), and perceived neglect (Sobel test: $Z=-3.43, p<0.000$ ) were all significant mediators of the relationship between actual wait duration and wait evaluations. (Beta coefficients for Sobel tests in Table III). Similar results were obtained for the one-tailed mediation tests for the relationship between PWD[3] and wait evaluations, (PB: $Z=-3.31, p<, 0.000, P C: Z=-2.75, p<0.000$, WT: $Z=-3.68, p<0.000, P N: Z=-3.24$, $p<0.000)$. (Beta coefficients for Sobel tests in Table V). These results support H1a-d, a relationship between PWD and the psychological factors, and $\mathrm{H} 2 \mathrm{a}-\mathrm{d}$, the mediating effect of the psychological factors.

Separate multiple regression analyses found that perceived and actual wait duration were significantly related to wait evaluations even after controlling for the mediating variables (perceived: 
$B=-.052, F=36.245, p<0.0001$, actual: $B=-0.078, F=45.014, p<0.0001)$, indicating that the psychological factors only partially mediated this relationship (Baron and Kenny, 1986). Finally, correlation analysis indicated a significant and positive $\left(r^{2}=0.294, p<0.0001\right)$ relationship between wait evaluations and service encounter evaluations. (Beta coefficients for Sobel tests are located in Table IV).

\begin{tabular}{|c|c|c|c|c|c|}
\hline Construct and indicators & $\begin{array}{l}\text { Standardized } \\
\text { loadings }\end{array}$ & $\begin{array}{c}t \text {-test } \\
(\text { all sig } \\
p<0.001)\end{array}$ & $\begin{array}{l}\text { Reliability } \\
\text { (composite in } \\
\text { italics) }\end{array}$ & $\begin{array}{c}\text { Variance } \\
\text { extracted estimate }\end{array}$ & \\
\hline Service evaluations & & & 0.874 & 0.702 & \\
\hline V1 (unfavorable/favorable) & 0.961 & 11.94 & 0.924 & & \\
\hline V2 (negative/positive) & 0.829 & 9.659 & 0.687 & & \\
\hline $\begin{array}{l}\text { V3 (how much old you like the } \\
\text { datepages.com overall?) }\end{array}$ & 0.704 & 7.826 & 0.496 & & \\
\hline Wait evaluation & & & 0.918 & 0.74 & \\
\hline V4 (annoyed/pleased) & 0.689 & 7.79 & 0.475 & & \\
\hline V5 (unhappy/happy) & 0.963 & 12.5 & 0.927 & & \\
\hline V6 (irritated/not irritated) & 0.871 & 11.035 & 0.759 & & \\
\hline $\begin{array}{l}\text { V7 (very unacceptable/very } \\
\text { acceptable) }\end{array}$ & 0.893 & 11.512 & 0.797 & & \\
\hline Perceived neglect & & & 0.819 & 0.603 & \\
\hline $\begin{array}{l}\text { V8 (It was disrespectful of them to } \\
\text { make me wait) }\end{array}$ & 0.805 & 9.66 & 0.648 & & \\
\hline $\begin{array}{l}\text { V9 (no one was paying attention } \\
\text { to me) }\end{array}$ & 0.677 & 7.517 & 0.458 & & \\
\hline VI0 (I was being neglected) & 0.839 & 10.31 & 0.704 & & \\
\hline Perceived boredom & & & 0.902 & 0.759 & \\
\hline V11 (exciting/unexciting) & 0.92 & 11.812 & 0.846 & & \\
\hline V12 (fun/not fun) & 0.682 & 7.709 & 0.465 & & \\
\hline V13 (boring/interesting) & 0.983 & 12.24 & 0.966 & & \\
\hline Perceived control & & & 0.851 & 0.454 & \\
\hline V14 (in control/no control) & 0.537 & 5.506 & 0.288 & & \\
\hline V15 (submissive/dominant) & 0.764 & 8.67 & 0.584 & & \\
\hline V16 (helpless/confident) & 0.589 & 6.151 & 0.347 & & \\
\hline V17 (weak/strong) & 0.646 & 6.902 & 0.417 & & \\
\hline V18 (helpless/competent) & 0.792 & 9.13 & 0.627 & & \\
\hline V19 (controlled/controlling) & 0.605 & 6.361 & 0.366 & & \\
\hline V20 (Influenced/influential) & 0.741 & 8.294 & 0.549 & & \\
\hline Perceived wasted time & & & 0.902 & 0.699 & \\
\hline $\begin{array}{l}\text { V21 (wait was a complete waste } \\
\text { of time) } \\
\text { V22 (wait took time away from }\end{array}$ & 0.859 & 10.696 & 0.738 & & \\
\hline other things) & 0.832 & 10.17 & 0.692 & & \\
\hline $\begin{array}{l}\text { V23 (wait made my planned } \\
\text { schedule tight) }\end{array}$ & 0.918 & 11.958 & 0.843 & & \\
\hline $\begin{array}{l}\text { V24 (wait made me late for another } \\
\text { appointment) }\end{array}$ & 0.722 & 8.26 & 0.521 & & $\begin{array}{l}\text { Table II. } \\
\text { Study } 2 \text { CFA results }\end{array}$ \\
\hline
\end{tabular}

\section{Discussion}

The psychological factors partially mediated the relationship between both actual and PWD and wait evaluations. This means that actual wait time partially drives the variability in perceived wasted time, perceived control, perceived boredom, and perceived neglect. Further, wait evaluations were shown to have a positive relationship with service encounter evaluation. Therefore, the relationships proposed in the model in Figure 2 hold, and the proposed waiting perceptions framework can be used to evaluate the effect of situational and environmental variables in the servicescape on customers' reactions to the wait experience.

Actual and PWD still had a significant relationship with wait evaluations even after controlling for the psychological factors (partial mediation). This direct effect of wait duration on wait evaluation 
suggests that people have an ingrained dislike of waiting separate from its impact on their psychological well-being. Therefore, there is only so much positive effect that can be gained from perception management strategies. Customers will continue to seek out opportunities to minimize their wait times, so firms must continue to find creative ways to reduce or eliminate waits.

Table III.

Study 2: beta coefficients from separate regressions of actual time on each mediator and each mediator on wait evaluations

\begin{tabular}{lcccc}
\hline Construct & \multicolumn{2}{c}{ Actual wait time } & \multicolumn{2}{c}{ Wait evaluations } \\
\hline Perceived boredom & 0.198 & $\left(0.038^{* * * *}\right)$ & -0.161 & $\left(0.033^{* * * *}\right)$ \\
Perceived control & -0.146 & $(0.030 * * *)$ & 0.125 & $\left(0.046^{* * * *)}\right.$ \\
Perceived wasted time & 0.204 & $\left(0.038^{* * * *)}\right.$ & -0.199 & $\left(0.031^{* * * *}\right)$ \\
Perceived neglect & 0.186 & $(0.035 * * *)$ & -0.166 & $\left(0.037^{* * * *}\right)$ \\
Note: ${ }^{*} p<0.0001, * * p<0.001, * * * p<0.01, * * * * p<0.05, * * * * p<0.10$ & \\
\hline
\end{tabular}

Table IV.

Study 2: beta coefficients from separate regressions of perceived time on each mediator, and each mediator on wait evaluations

\begin{tabular}{lrrrr}
\hline Construct & \multicolumn{2}{c}{ PWD } & \multicolumn{2}{c}{ Wait evaluations } \\
\hline Perceived boredom & 0.175 & $\left(0.042^{* * * *}\right)$ & -0.206 & $(0.036 * * *)$ \\
Perceived control & -0.132 & $(0.032 * * *)$ & 0.189 & $(0.017 * * *)$ \\
Perceived wasted time & 0.180 & $\left(0.042^{* * * *}\right)$ & -0.243 & $(0.034 * * *)$ \\
Perceived neglect & 0.155 & $(0.039 * * *)$ & -0.219 & $(0.039 * * *)$ \\
Note: ${ }^{*} p<0.0001,{ }^{* *} p<0.001, * * * p<0.01,{ }^{* * * *} p<0.05, * * * * *$ \\
\end{tabular}

\section{Study 3}

The purpose of Study 3 was to test the effectiveness of the framework in evaluating the impact of situational and environmental variables using occupied time and time filling activity type (active vs passive and choice vs no choice) as the variables. The hypotheses for Study 3 are shown in Figure 3.

\section{A. Methodology}

Study 3 was similar in design to Study 2, except that at log in the subjects were randomly assigned to one of six waiting conditions (no wait, empty wait, passive no choice, passive choice, active no choice, and active choice), and all wait durations were set at ten minutes. Computer games represented active fillers and videos, passive[4]. Subjects in the filled wait conditions were either given a game or video, or they had a choice of four games or four videos. The 165 undergraduate subjects primarily participated in the experiment for course credit, but some received a $\$ 5$ gift certificate from a local coffee shop. As in Studies 1 and 2, the subjects were primarily female (72 percent), and the average age was 20.7 years (ranged from 18 to 29). The survey instrument from Study 2 was used, with the addition of one item measuring how much the subjects liked the wait time activity (measured on a seven-point Likert scale). 


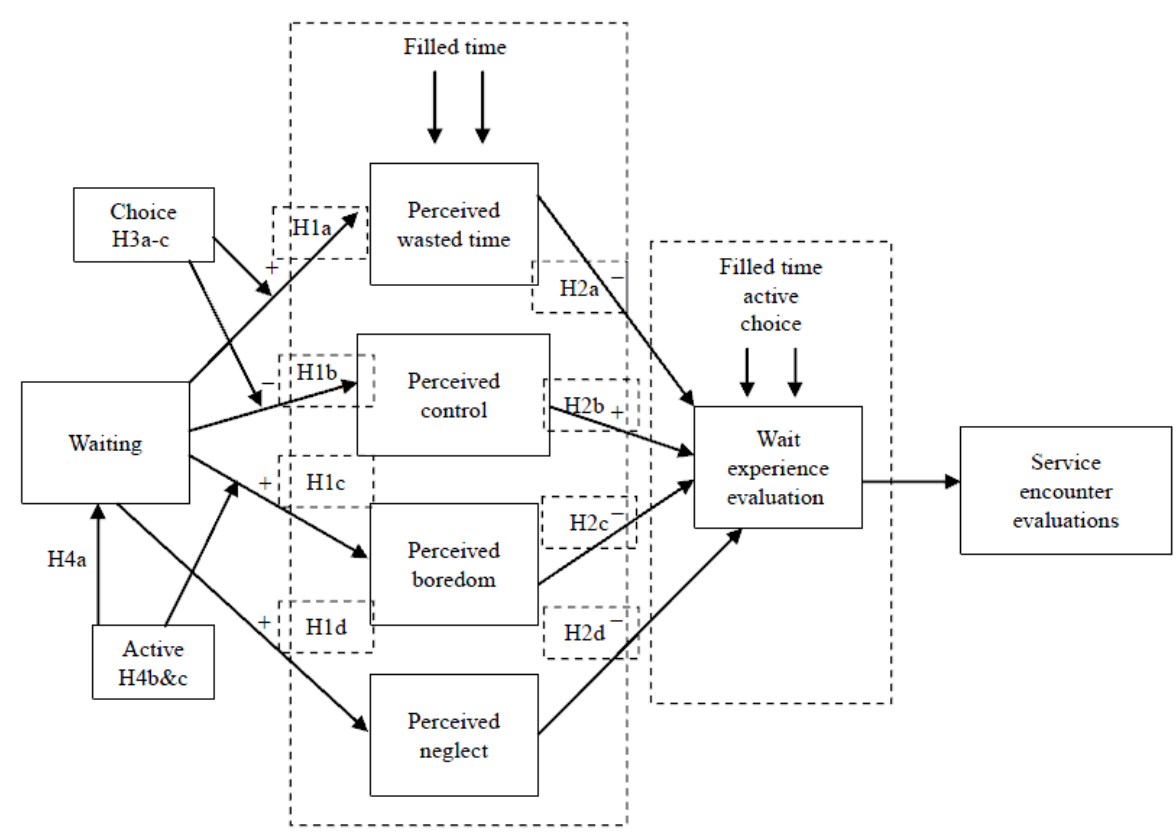

Figure 3. Study 3 summary of hypotheses

Five mutually orthogonal linear contrasts were created to determine the impact of the treatment type on the mean value of the constructs (Figure 4):

- wait/no wait;

- filled time/empty time;

- active/passive;

- choice/no choice; and

- interaction of active and choice.

Treatment means were calculated for each study variable, and a t-test determined whether the difference between the treatment means (contrast value) was statistically significant. Table $V$ displays the coefficients for the five orthogonal contrasts.

\section{B. Results}

CFA in SAS 9.13 validated the underlying factor structure of the study measures. All t-values were significant and most factor loadings were .0 .40 . The $x^{2} / d f$ ratio was within the desirable range of between 1 and 3 (Marsh and Hocevar, 1985). The normed fit index (0.88) and comparative fit index (0.85) were close to the recommended range of 0.90 (Bentler, 1990). Composite reliabilities were as follows: perceived wasted time (0.90), perceived control (0.84), perceived boredom (0.88), perceived neglect (0.83), wait evaluation (0.91), service evaluation (0.88). Scale items were averaged for the subsequent analysis (Table VI).

Orthogonal contrast results are presented below: 
Wait/no wait. Subjects who had to wait reported a significantly $(p<0.001)$ higher perceived time estimate, and higher feelings of perceived wasted time, boredom and neglect than those who did not have to wait. They also felt less control and had lower wait evaluations (Table VII).

Figure 4.

Example equation orthogonal contrast

$$
\text { Filled - Empty }=\left[\frac{\frac{\mu_{P N C}}{n_{P N C}}+\frac{\mu_{P C}}{n_{P C}}+\frac{\mu_{A N C}}{n_{A N C}}+\frac{\mu_{A C}}{n_{A C}}}{4}\right]-\frac{\mu_{E W}}{n_{N W}}+0 *\left(\frac{\mu_{N W}}{n_{N W}}\right)
$$

Notes: $\mu$, mean perceived boredom; $P$, passive; $A$, active; $N C$, no choice; $C$, choice; EW, empty wait; NW, no wait
Table V.

Study 3 orthogonal contrast coefficients

\begin{tabular}{lcccccr}
\hline Contrast & $\begin{array}{c}\text { Passive no } \\
\text { choice }\end{array}$ & $\begin{array}{c}\text { Passive } \\
\text { choice }\end{array}$ & $\begin{array}{c}\text { Condition } \\
\text { Active no } \\
\text { choice }\end{array}$ & $\begin{array}{c}\text { Active } \\
\text { choice }\end{array}$ & Empty & $\begin{array}{c}\text { No } \\
\text { wait }\end{array}$ \\
\hline Wait-no wait & 0.2 & 0.2 & 0.2 & 0.2 & 0.2 & -1 \\
Filled-unfilled & 0.25 & 0.25 & 0.25 & 0.25 & -1 & 0 \\
Active-passive & -0.5 & -0.5 & 0.5 & 0.5 & 0 & 0 \\
Choice-no choice & -0.5 & 0.5 & -0.5 & 0.5 & 0 & 0 \\
Interaction Choice/ & 1 & -1 & -1 & 1 & 0 & 0 \\
Active & 1 & & & & &
\end{tabular}

\begin{tabular}{|c|c|c|c|c|}
\hline Construct and indicators & $\begin{array}{l}\text { Standardized } \\
\text { loadings }\end{array}$ & $\begin{array}{l}t \text {-test (all } \\
\text { sig at } \\
p<0.001 \text { ) }\end{array}$ & $\begin{array}{l}\text { Reliability } \\
\text { (composite in } \\
\text { italics) }\end{array}$ & $\begin{array}{l}\text { Variance } \\
\text { extracted } \\
\text { estimate }\end{array}$ \\
\hline Service evaluations & & & 0.875 & 0.704 \\
\hline V1 (unfavorable/favorable) & 0.981 & 15.580 & 0.962 & \\
\hline V2 (negative/positive) & 0.735 & 10.450 & 0.540 & \\
\hline $\begin{array}{l}\text { V3 (how much did you like the } \\
\text { datepages.com overall?) }\end{array}$ & 0.781 & 11.300 & 0.610 & \\
\hline Wait evaluation & & & 0.911 & 0.722 \\
\hline V4 (annoyed/pleased) & 0.949 & 16.050 & 0.901 & \\
\hline V5 (unhappy/happy) & 0.810 & 12.370 & 0.656 & \\
\hline V6 (irritated/not irritated) & 0.889 & 14.330 & 0.790 & \\
\hline V7 (very unacceptable/very acceptable) & 0.735 & 10.740 & 0.540 & \\
\hline Perceived neglect & & & 0.828 & 0.625 \\
\hline $\begin{array}{l}\text { V8 (it was disrespectful of them to make } \\
\text { me wait) }\end{array}$ & 0.801 & 12.190 & 0.642 & \\
\hline V9 (no one was paying attention to me) & 0.577 & 7.850 & 0.333 & \\
\hline V10 (I was being neglected) & 0.949 & 15.990 & 0.901 & \\
\hline Perceived boredom & & & 0.883 & 0.719 \\
\hline V11 (exciting/unexciting) & 0.892 & 14.040 & 0.796 & \\
\hline V12 (fun/not fun) & 0.698 & 9.930 & 0.487 & \\
\hline V13 (boring/interesting) & 0.935 & 15.140 & 0.874 & \\
\hline Perceived control & & & 0.841 & 0.440 \\
\hline V14 (in control/no control) & 0.602 & 8.030 & 0.362 & \\
\hline V15 (submissive/dominant) & 0.828 & 12.420 & 0.686 & \\
\hline V16 (helpless/confident) & 0.679 & 9.380 & 0.461 & \\
\hline V17 (weak/strong) & 0.497 & 6.390 & 0.247 & \\
\hline V18 (helpless/competent) & 0.633 & 8.560 & 0.401 & \\
\hline V19 (controlled/controlling) & 0.492 & 6.330 & 0.242 & \\
\hline V20 (influenced/influential) & 0.825 & 12.350 & 0.681 & \\
\hline Perceived wasted time & & & 0.901 & 0.694 \\
\hline V21 (wait was a complete waste of time) & 0.890 & 14.510 & 0.792 & \\
\hline $\begin{array}{l}\text { V22 (wait took time away from other } \\
\text { things) }\end{array}$ & 0.778 & 11.700 & 0.605 & \\
\hline $\begin{array}{l}\text { V23 (wait made my planned schedule } \\
\text { tight) }\end{array}$ & 0.884 & 14.330 & 0.781 & \\
\hline $\begin{array}{l}\text { V24 (wait made me late for another } \\
\text { appointment) }\end{array}$ & 0.774 & 11.600 & 0.599 & \\
\hline
\end{tabular}


Filled wait/empty wait. There was no significant difference in wait time estimates between subjects whose time was filled during the wait and those that had nothing to do (Table VII). However, subjects whose time was filled during the wait felt significantly less bored than subjects that had an empty wait, and they reported higher wait evaluations. Filled (vs. unfilled) wait time had no significant effect on subjects' perceptions of perceived wasted time, control or neglect (Table VII).

Influence of activity type. Three orthogonal contrasts compared the influence of activity type on reactions to the wait experience (active/passive, choice/no choice, and interaction choice/active). Although the point estimates for the orthogonal contrasts were in the hypothesized direction, there were no significant differences for any of the contrasts, indicating that a relationship between activity type and wait perceptions could not be found. Therefore, H3a-c, influence of choice, and H4b, influence of active vs passive, are not statistically supported by our data (Table VII).

\begin{tabular}{|c|c|c|c|c|c|c|c|}
\hline & $\begin{array}{l}\text { PWD } \\
\text { (mins) }\end{array}$ & $\begin{array}{c}\text { Perceived wasted } \\
\text { time }^{L}\end{array}$ & $\begin{array}{l}\text { Perceived } \\
\text { control }^{\text {sd }}\end{array}$ & $\begin{array}{l}\text { Perceived } \\
\text { boredom }^{\text {sd }}\end{array}$ & $\begin{array}{l}\text { Perceived } \\
\text { neglect }\end{array}$ & $\begin{array}{l}\text { Wait } \\
\text { evals }^{\text {STD }}\end{array}$ & $\begin{array}{l}\text { Service } \\
\text { evals }^{\text {STD }}\end{array}$ \\
\hline Wait-no wait & $8.035^{*}$ & $2.346^{*}$ & $-1.133^{*}$ & $1.033^{*}$ & $1.812^{*}$ & $-1.289^{*}$ & -0.267 \\
\hline Filled-unfilled & -1.002 & -0.173 & -0.123 & $-1.269^{*}$ & 0.242 & $0.396^{* *}$ & -0.178 \\
\hline Active-passive & 0.320 & 0.001 & -0.021 & -0.230 & -0.197 & -0.021 & 0.021 \\
\hline Choice-no choice & 0.140 & 0.115 & 0.108 & -0.628 & $-0.606^{* * * * *}$ & 0.106 & 0.053 \\
\hline $\begin{array}{l}\text { Interaction choice/ } \\
\text { active }\end{array}$ & -2.954 & 0.197 & 0.118 & -0.163 & -0.205 & 0.012 & -0.130 \\
\hline $\begin{array}{l}\text { Notes: }{ }^{*} p<0.0001 \\
\text { STD, standardized }\end{array}$ & $*^{*} p<0.001$ & $* * * p<0.01, \quad * * * *$ & $5, * * * * *$ & $\mathrm{~L}$, likert s & -7), sd, sema & differential & $(-4$ to \\
\hline
\end{tabular}

\section{Discussion}

In this study, filled time decreased perceived boredom and increased wait evaluations, suggesting that customers that have something to do during the wait experience will be less bored, and more satisfied with their wait experience. This result empirically supports Chebat and Filiatrault's (1993) and Pruyn and Smidt's (1998) suggestions that longer perceived wait times and lower satisfaction results were caused by boring or routine time fillers. The fact that activity type was not significant suggests that it may not matter what customers are given to do during the wait, as long as it entertains them, they will be less bored, and happier overall with the service. The wait perceptions framework helped to identify the impact of the environmental factor (filled vs unfilled time) on a specific process underlying the wait experience.

While it may seem more natural to provide entertaining wait time activities at hedonistic services, functional services like banks, cafeterias and grocery stores can apply the same principles. For example, at security checkpoints, rather than using the typical signage or security announcements, McCarran Airport in Las Vegas presents a series of videos in which well-known Las Vegas characters 
(such as the Blue Man Group and Penn and Teller) go through the security screening process (www. mccarran.com/traveltips1.asp). However, managers need to be sensitive to the type of service and the appropriateness of the chosen wait activities. Miller et al. (2008) found that commonly used techniques, such as providing wait time estimates, have a different effect on customer perceptions during negative service events (i.e. medical visits) than positive ones, so managers must be sensitive to the appropriateness of the chosen activity.

In this experiment, there were no significant differences in perceived wait time between filled and unfilled time or by activity type. These results support previous filled time research (Katz et al., 1991), but contradict the conventional wisdom that occupied time feels shorter than unoccupied time (Maister, 1985; Larson, 1987).

Several authors have described cases where complaints about excessive waits caused managers to add time fillers to the wait environment ostensibly to make waits feel shorter. However, the subsequent improvements in wait perceptions may have been attributed to the incorrect cause (Maister, 1985; Larson, 1987; Baker and Cameron, 1996). For example, those previous authors attributed the reduction in customer complaints about slow elevators when a mirror was installed in the elevator lobby to a reduction in perceived waiting time (Larson, 1987) but did not empirically validate this claim. This study suggests that the changes probably made the wait experience more pleasant because customers had something entertaining to do during the wait (look in the mirror), not that the wait felt shorter.

Maister's (1985) propositions on the psychology of waiting, which include occupying wait time, outline eight conditions that make waits "feel shorter." While his list of conditions rings true, this research suggests an alternate explanation for why they improve wait perceptions. It could be that it is not that the wait feels shorter, but rather the wait experience is more pleasant. The fact that Maister (1985) chose to describe this more pleasant experience by saying that the waits feel shorter speaks to the notion that people have an ingrained dislike for waiting. Although some of his conditions have been empirically shown to improve wait perceptions, as in this study, research has yet to validate any connection with reductions in perceived wait time. The framework proposed in this study could assist in isolating the effects of the situational and environmental factors in Maister's propositions on the processes underlying the wait experience, and also provide service managers guidance in positively influencing customer perceptions. 


\section{Directions for future research}

This study is only the first step in validating a wait perceptions framework and investigating the situational and environmental variables that affect the wait experience. Results of this study suggest that there could be a difference in waiting perceptions based on the service context. For example, perceived wasted time was a highly significant mediator in this study, and delay of gratification was barely significant. In hedonistic services, like amusement parks, delay of gratification might be an equally, or more, important psychological factor. Additionally, Studies 2 and 3 used an on-line service, which may cause different reactions than a live service encounter.

This study concentrated on short to medium duration waits (maximum of ten minutes), typical at a bank or grocery store, but far shorter than waits can be at some restaurants, airports and theme parks. It is likely that reactions to the wait experience would change in longer duration waits (Zakay, 1989; Taylor, 1994; Hui and Tse, 1996; Oakes, 2003), and little research has investigated waits exceeding 15 minutes (Mann, 1969; Oakes, 2003).

Although not empirically validated, findings in Study 3 suggested that the subjects' lack of familiarity with the service led to anxiety about the cause of the wait, and created heightened focus on the wait duration. Familiarity leads to expectations about the wait experience, which have been shown to strongly influence duration estimates (Hui and Tse, 1996) and satisfaction (Lee and Lambert, 2000). For example, "regulars" (frequent diners) can relax and enjoy drinks at the bar during the wait without feeling the need to watch other customers being seated or to check back with the hostess stand, whereas new customers might feel the need to monitor the seating process to ensure that the firm is treating them fairly. Less focus on monitoring the wait might give customers more mental capacity to focus on the wait time activity (Zakay, 1989), and change their perception of the wait duration or their reaction to the wait experience.

Finally, future theoretical and empirical research should specifically examine duration effects in waiting time intervals. Researchers found that different types of activities resulted in different time estimates during a fixed time interval (Ornstein, 1969; Burnside, 1971; Hogan, 1978; Zakay, 1989; Kellaris and Kent, 1992; Kahneman, 1994; Csikszentmihalyi, 1996, 1997), but in these time intervals, the provided activity was the primary purpose. The perceptual differences when the wait is the primary purpose of the time interval have not been thoroughly investigated. 


\section{Summary}

Situational and environmental variables in the waiting environment portion of the servicescape have been shown to alter the well-established relationship between perceived waiting duration and satisfaction, indicating that the processes underlying this relationship are not well understood. This series of studies proposed and empirically evaluated the psychological factors that mediate this relationship, showing that perceived wasted time, perceived control, perceived boredom, and perceived neglect influence the relationship between perceived waiting duration and satisfaction, particularly in functional service contexts.

To test the effectiveness of the framework in modeling the impact of environmental variables on customer perceptions, an experiment was designed to evaluate the impact of occupied wait time and time filling activity. Some authors have suggested that occupying customer wait time will improve satisfaction because occupied time feels shorter than unoccupied time (Maister, 1985; Larson, 1987); however, research has not always supported this relationship. This study showed that, while filled time does not feel shorter than unfilled time, giving customers something to do during the wait will improve the wait experience if it reduces boredom. A more in-depth understanding of customers' reactions to waiting, such as the importance of keeping customers from becoming bored during the wait, provides an opportunity for managers to improve overall service satisfaction.

Since peak experiences, positive and negative, influence perceptions of the service encounter as a whole (Chase and Dasu, 2001; Dixon and Verma, 2009), managers should carefully consider the design of the wait experience and wait environment, as an integral part of the entire service experience. Practitioners should also keep in mind, that simply providing something to do during the wait will not completely eliminate the impact of waiting time on satisfaction. In this study, filled time had no effect on perceptions of perceived wasted time, control or neglect, and these factors will continue to reduce wait evaluations as wait time increases. Further, the direct relationship between perceived wait time and wait evaluations suggests that no matter how pleasant the wait experience is for the customers, they still dislike waiting by nature. Therefore, service providers must continue to manage the actual duration of the wait along with managing perceptions of the wait experience.

Notes

1. Three minutes was the average wait duration reported in Study 1 (rounded to the nearest minute), and ten minutes, the maximum reported wait duration from Study 
1 , has been used in multiple wait time studies as a representation of medium duration waits (Hui and Tse, 1996; Hui et al., 1998; Taylor, 1995).

2. Responses to the survey were anonymous, making it impossible to test if there were any significant differences in responses between the two compensation methods.

3. Subject's wait duration estimates were significantly higher than actual wait duration for the three minute actual wait condition (mean, 3.97; SD, 1.28), but no different than the actual duration for the zero (mean, 1.06, SD, 0.43) or ten minute (mean, 9.45; SD, 3.44) wait conditions. Subjects were asked to report estimated wait duration to the nearest minute, given a slight delay for page loading, most subjects in the zero wait condition rounded their estimates to one minute. While the mean for the zero wait condition was significantly different from zero, it was not significantly different from one minute.

The games and videos were pre-tested for relevance to the study population. A manipulation pretest on a similar population showed that subjects felt the games (mean $=0.94$ out of $4=$ "active") were significantly more active than the videos (mean=-1.48 out of $4=$ "Active") $(p<0.001)$ (Zaichowsky, 1985). However, there was no significant difference $(p=0.59)$ in how much the subjects liked the activities (mean games $=4.10$ and mean video $=3.80$ out of $7=$ "extremely so"), nor was there a significant difference $(p=0.43$ ) in how interesting the subjects found the games (mean $=0.17$ out of $4=$ "interesting") versus the videos (mean $=-0.37$ out of $4=$ "interesting").

\section{References}

Ajzen, I. and Fishbein, M. (1980), Understanding Attitudes and Predicting Social Behavior, Prentice-Hall, Englewood Cliffs, NJ.

Antonides, G., Verhoef, P.C. and van Aalst, M. (2002), "Consumer perception and evaluation of waiting time: a field experiment", Journal of Consumer Psychology, Vol. 12 No. 3, pp. 193-202.

Averill, J.R. (1973), "Personal control over aversive stimuli and its relationship to stress", Psychological Bulletin, Vol. 80 No. 4, pp. 286-303.

Baker, J. and Cameron, M. (1996), "The effects of the service environment on affect and consumer perceptions of waiting time: an integrative review and research propositions", Journal of the Academy of Marketing Science, Vol. 24 No. 2, pp. 338-49. 
Baron, R.M. and Kenny, D.A. (1986), "The moderator-mediator variable distinction in social psychological research: conceptual, strategic and statistical considerations", Journal of Personality and Social Psychology, Vol. 51 No. 6, pp. 1173-82.

Baum, A. and Greenburg, C.I. (1975), "Waiting for a crowd: the behavioral and perceptual effects of anticipated crowding", Journal of Personality and Social Psychology, Vol. 32 No. 4, pp. 671-9.

Bentler, P.M. (1990), “Comparative fit indexes in structural models”, Psychological Bulletin, Vol. 107 No. 1, pp. 238-46.

Berry, L.L., Seiders, K. and Grewal, D. (2002), "Understanding service convenience", Journal of Marketing, Vol. 66 No. 3, pp. 1-17.

Bielen, F. and Demoulin, N. (2007), "Waiting time influence on the satisfaction-loyalty relationship in services", Managing Service Quality, Vol. 17 No. 2, p. 174.

Bitner, M. (1990), "Evaluating service encounters: the effects of physical surroundings and employee responses", Journal of Marketing, Vol. 54 No. 2, pp. 69-82.

Bitner, M.J. (1992), "Servicescapes: the impact of physical surroundings on customers and employees", Journal of Marketing, Vol. 56 No. 2, pp. 57-71.

Burger, J.M. (1987), "Increased performance with increased personal control: a self-presentation interpretation", Journal of Experimental Social Psychology, Vol. 23 No. 4, pp. 350-60.

Burnside, W. (1971), "Judgment of short-time intervals while performing mathematical tests", Perception and Psychophysics, Vol. 9 No. 5, pp. 404-6.

Burt, C.D.B., Mitchell, D.A., Raggatt, P.T.F., Jones, C.A. and Cowan, T.M. (1995), “A snapshot of autobiographical memory retrieval characteristics", Applied Cognitive Psychology, Vol. 9 No. 1, pp. 61-74.

Carmon, Z.J., Shanthikumar, G. and Carmon, T.F. (1995), “A psychological perspective on service segmentation models: the significance of accounting for consumers' perceptions of waiting and service", Management Science, Vol. 41 No. 11, pp. 1806-15.

Chase, R.B. and Dasu, S. (2001), "Want to perfect your company's service? Use behavioral science", Harvard Business Review, Vol. 76 No. 6, pp. 78-84.

Chebat, J.C. and Chebat, G.C. (1995), "The impact of mood on time perception, memorization and acceptance of waiting", Genetic, Social \& General Psychology Monographs, Vol. 121 No. 4, pp. 411-25.

Chebat, J.C. and Filiatrault, P. (1993), "The impact of waiting in line on consumers", The International Journal of Bank Marketing, Vol. 11 No. 2, pp. 35-41. 
Churchill, G.A. (1979), “A paradigm for developing better measures of marketing constructs”, Journal of Marketing Research, Vol. 16 No. 1, pp. 64-73.

Clemmer, E.C. and Schneider, B. (1989), "Towards understanding and controlling customer dissatisfaction during peak demand times", in Bitner, M.J. and Crosby, L.A. (Eds), Designing a Winning Service Strategy, Proceedings from 7th Annual Services Marketing Conference, Chicago, IL.

Csikszentmihalyi, M. (1996), Creativity: Flow and the Psychology of Discovery and Invention, Harper Collins, New York, NY.

Csikszentmihalyi, M. (1997), Finding Flow, Basic Books, New York, NY.

Davis, M.M. and Heineke, J. (1998), "How disconfirmation, perception and actual waiting times impact customer satisfaction", International Journal of Service Industry Management, Vol. 9 No. 1, pp. 64-73.

Davis, M.M. and Volmann, T.E. (1990), “A framework for relating waiting time and customer satisfaction in a service operation", Journal of Services Marketing, Vol. 4 No. 1, pp. 61-9.

Dixon, M. and Verma, R. (2009), Working paper, Cornell University, Ithaca, NY.

Dube-Rioux, L., Schmidt, B.H. and Leclerc, F. (1989), “Consumer's reactions to waiting: when delays affect perceptions of service quality", Advances in Consumer Research, Vol. 16 No. 1, pp. 59-63.

Feinberg, R.A. and Smith, P. (1989), "Misperception of time in the sales transaction", Advances in Consumer Research, Vol. 16 No. 1, pp. 56-8.

Folkes, V., Kolestsky, S. and Graham, J.L. (1987), "A field study of causal inferences and consumer reaction: the view from the airport", Journal of Consumer Research, Vol. 13 No. 4, pp. 534-9.

Higie, R.A. and Feick, L.F. (1989), "Enduring involvement: conceptual and measurement issues", Advances in Consumer Research, Vol. 16 No. 1, pp. 690-6.

Hogan, H.W. (1978), "Time perception and stimulus preference as a function of stimulus complexity", Journal of Personality and Social Psychology, Vol. 31 No. 1, pp. 32-5.

Hornik, J. (1984), "Subjective vs. objective time measures: a note on the perception of time in consumer behavior", Journal of Consumer Research, Vol. 11 No. 1, pp. 615-8.

Houston, M.B., Bettencourt, L.A. and Wenger, S. (1998), "The relationship between waiting in a service queue and evaluations of service quality: a field theory perspective", Psychology \& Marketing, Vol. 15 No. 8, pp. 735-53.

Hui, M.K. and Bateson, J.E.G. (1991), "Perceived control and the effect of crowding and consumer choice on the service experience", Journal of Consumer Research, Vol. 18 No. 2, pp. 174-84. 
Hui, M.K. and Tse, D.K. (1996), "What to tell customers in waits of different lengths: an integrated model of service evaluations", Journal of Marketing, Vol. 60 No. 2, pp. 81-90.

Hui, M.K., Dube, L. and Chebat, J.C. (1997), "The impact of music on consumers' reactions to waiting for service", Journal of Retailing, Vol. 73 No. 1, pp. 87-104.

Hui, M.K., Thakor, M.V. and Gill, R. (1998), “The effects of delay type and service stage on consumers' reaction to waiting", Journal of Consumer Research, Vol. 24 No. 4, pp. 469-79.

Jacoby, J., Szybillo, G.J. and Berning, C.K. (1976), "Time and consumer behavior: an interdisciplinary overview", Journal of Consumer Research, Vol. 2 No. 4, pp. 320-39.

Kahneman, D. (1994), "New challenges to the rationality assumption", Journal of Institutional and Theoretical Economics, Vol. 150 No. 1, pp. 18-36.

Katz, K.L., Larson, B. and Larson, R.C. (1991), “Prescription for the waiting in line blues: entertain, enlighten and engage", Sloan Management Review, Vol. 32 No. 2, pp. 44-53.

Kellaris, J.J. and Kent, R.J. (1992), “The influence of music on consumers' temporal perceptions: does time fly when you are having fun?", Journal of Consumer Psychology, Vol. 1 No. 4, pp. 365-76.

Klapp, O.E. (1986), Overload and Boredom: Essays on the Quality of Life in the Information Age, Greenwood Press, New York, NY.

Koseluk, C. (2004), “Are we there yet?”, Amusement Business, Vol. 116 No. 25, pp. 14-17.

Langer, E.J. and Rodin, J. (1976), "The effects of choice and enhanced personal responsibility for the aged: a field experiment in an institutional setting", Journal of Personal and Social Psychology, Vol. 34 No. 2, pp. 191-8.

Langer, E.J. and Saegart, S. (1977), "Crowding and cognitive control”, Journal of Personality and Social Psychology, Vol. 35 No. 3, pp. 175-82.

Larson, R.C. (1987), "Perspective on queues: social justice and the psychology of queueing”, Operations Research, Vol. 35 No. 3, pp. 895-905.

Leclerc, F., Schmitt, B.H. and Dube, L. (1995), "Waiting time and decision making: is time like money", Journal of Consumer Research, Vol. 22 No. 1, pp. 110-9.

Lee, W. and Lambert, C.U. (2000), "Impact of waiting time evaluation on service quality and satisfaction in food service operations", Food Service Research International, Vol. 12 No. 4, pp. 241-54.

Lewin, K. (1943), “Defining the field at a given time”, Psychological Review, Vol. 50 No. 3, pp. 292-310. Maister, D.H. (1985), "The psychology of waiting lines", in Czepiel, J.A., Solomon, M.R. and Surprenant, C.F. (Eds), The Service Encounter: Managing Employee/Customer Interaction in Service Businesses, Lexington Books, Lexington, MA, pp. 113-23. 
Mann, L. (1969), "Queue culture: the waiting line as a social system”, American Journal of Sociology, Vol. 75 No. 3, pp. 340-54.

Marsh, H.W. and Hocevar, D. (1985), "Application of confirmatory factor analysis to the study of selfconcepts: first-and higher-order factor models and their invariance across groups", Psychological Bulletin, Vol. 97 No. 3, pp. 562-82.

Miller, E.G., Kahn, B. and Luce, M. (2008), “Consumer wait management strategies for negative service events: a coping approach", Journal of Consumer Research, Vol. 34 No. 5, pp. 635-48.

Mischel, W. (1974), "Processes in delay of gratification", in Birkowitz, L. (Ed.), Advances in Experimental Social Psychology, Vol. 7, Academic Press, New York, NY, pp. 249-92.

Namasivayam, K. and Hinkin, T.R. (2003), "The customer's role in the service encounter: the effects of control and fairness", Cornell Hotel \& Restaurant Administration Quarterly, Vol. 44 No. 3, pp. 2636.

Nguyen, T.T. and Belk, R.W. (2007), "This we remember: consuming representation via the web posting of war photographs", Consumption Markets and Culture, Vol. 10 No. 3, pp. 251-91.

Nie, W. (2000), "Waiting: integrating social and psychological perspectives in operations management", Omega and The International Journal of Management Science, Vol. 28 No. 6, pp. 611-29.

Oakes, S. (2003), "Musical tempo and waiting perceptions", Psychology \&Marketing, Vol. 20 No. 8, pp. 685-705.

Ornstein, R.E. (1969), On the Experience of Time, Penguin, Harmondsworth.

Osuna, E.E. (1985), "The psychological cost of waiting", Journal of Mathematic Psychology, Vol. 29 No. 1, pp. 82-105.

Parasuraman, A., Zeithaml, V.A. and Berry, L.L. (1988), "SERVQUAL: a multiple-item scale for measuring consumer perception of service quality", Journal of Retailing, Vol. 64 No. 1, pp. 12-40.

Parasuraman, A., Zeithaml, V.A. and Leonard, L.B. (1985), “A conceptual model of service quality and its implication for future research", Journal of Marketing, Vol. 49 No. 4, pp. 41-50.

Pruyn, A. and Smidts, A. (1998), "The effect of waiting on satisfaction with the service: beyond objective time measurements", International Journal of Research in Marketing, Vol. 15 No. 4, pp. 321-34.

Saegert, S., Mackintosh, E. and West, S. (1975), "Two studies of crowding in urban public spaces", Environment \& Behavior, Vol. 7 No. 2, pp. 159-84.

Schwartz, B. (1975), Queuing and Waiting, University of Chicago Press, Chicago, IL. 
Sherrod, D.R., Hage, J.N., Halpern, P.L. and More, B.S. (1977), "The effects of personal causation and perceived control on responses to an aversive environment: the more control, the better", Journal of Experimental Social Psychology, Vol. 13 No. 1, pp. 14-27.

Staub, E., Tursky, B. and Schwartz, G. (1971), "Self-control and predictability: their effects on reactions to aversive stimulation", Environment \& Behavior, Vol. 18 No. 2, pp. 157-62.

Stokols, D. (1972), "On the distinction between density and crowding: some implications for future research", Psychological Review, Vol. 79 No. 3, pp. 275-7.

Stokols, D., Rall, M., Pinner, B. and Schopler, J. (1973), "Physical, social and personal determinants of the perception of crowding", Environment \& Behavior, Vol. 79 No. 3, pp. 275-7.

Sundstrom, E. (1975), "An experimental study of crowding: effects of room size, intrusion and goal blocking on non-verbal behavior, self-disclosure and self-reported stress", Journal of Personality and Social Pscyhology, Vol. 32 No. 4, pp. 645-54.

Szpiler, J.A. and Epstein, S. (1976), "Availability of an avoidance response as related to automatic arousal", Journal of Abnormal Psychology, Vol. 85 No. 1, pp. 73-82.

Taylor, S. (1994), "Waiting for service: the relationship between delays and evaluation of service quality", Journal of Marketing, Vol. 58 No. 2, pp. 56-69.

Taylor, S. (1995), "The effect of filled waiting time and service provider control over the delay on evaluations of service", Journal of the Academy of Marketing Science, Vol. 23 No. 1, pp. 38-48.

Tom, G. and Lucey, S. (1997), "A field study investigating the effect of waiting time on customer satisfaction", Journal of Psychology, Vol. 131 No. 6, pp. 655-60.

Troutwine, R. and O'Neal, E.C. (1981), "Volition, performance of a boring task and time estimation", Perceptual and Motor Skills, Vol. 52 No. 3, pp. 865-6.

Valins, S. and Baum, A. (1973), "Residential group size, social interaction and crowding", Environment \& Behavior, Vol. 5, pp. 421-39.

Verma, R., Thompson, G.M. and Louviere, J.J. (1999), “Configuring service operations in accordance with customer needs and preferences", Journal of Service Research, Vol. 1 No. 3, pp. 262-74.

Weijters, B., Rangarajan, D., Falk, T. and Schillewaert, N. (2007), “Determinants and outcomes of customers' use of self-service technology in a retail setting", Journal of Service Research, Vol. 10 No. 1, pp. 3-22. 